\title{
Degradation of oxide-passivated boron-diffused silicon
}

\author{
Andrew F. Thomson ${ }^{\text {a) }}$ and Keith R. McIntosh \\ Centre for Sustainable Energy Systems, Australian National University, Canberra, \\ Australian Capital Territory 0200, Australia
}

(Received 12 June 2009; accepted 15 July 2009; published online 3 August 2009)

\begin{abstract}
Recombination in oxide-passivated boron-diffused silicon is found to increase severely at room temperature. The degradation reaction leads to a 45 fold increase in emitter recombination that saturates in $\sim 120$ days, irrespective of whether the samples received a forming-gas anneal. The degradation was also examined for diffusions stored at 50,75 , and $100{ }^{\circ} \mathrm{C}$. The results indicate that the degradation follows a second-order reaction where the time constant of one component of the reaction is 10-40 times shorter than the other, and where the activation energy of the fast reaction is $0.19 \pm 0.05 \mathrm{eV}$. Subsequent to degradation, annealing in air reduces the recombination with increasing anneal temperature saturating at $\sim 300{ }^{\circ} \mathrm{C}$ to a value that is about four times higher than the predegradation value. A likely cause of this degradation is a reaction of atomic hydrogen at the silicon-oxide-silicon interface. (C) 2009 American Institute of Physics. [DOI: 10.1063/1.3195656]
\end{abstract}

High-efficiency silicon solar cells require low surface recombination. ${ }^{1}$ The best-known means to attain this is with oxide-passivated lightly doped diffusions where the dopant can be either phosphorus ${ }^{2,3}$ or boron., ${ }^{2,45}$ Many solar cell designs have employed the former, ${ }^{1,6,7}$ with phosphorusdiffused surfaces exhibiting excellent stability. ${ }^{8}$ The same is not always true of cells with boron-diffused surfaces, $4,5,9$ with the best-known example being the "passivated emitter rear-totally diffused" (PERT) cells fabricated from $n$-type silicon. After two years, the open-circuit voltage $\left(V_{\text {oc }}\right)$ of these cells had decreased by an average of $38.9 \mathrm{mV}$, equating to a $2 \%$ reduction in absolute efficiency. ${ }^{9}$

In this work, the recombination rate associated with oxide-passivated boron diffusions is monitored over many months. A severe increase in recombination that saturates in about 120 days is observed. We examine the extent of this degradation, the activation energy $E_{a}$ of the associated reaction, annealing of this degradation, and the underlying mechanism.

Symmetrical test structures were fabricated on floating zone, (100), $n$-type silicon wafers to allow photoconductance lifetime measurements of boron diffusions. The wafers were prepared by acid etching in hydrofluoric/nitric removing $\sim 20 \mu \mathrm{m}$ of saw damage, and Radio Corporation of American (RCA) cleaning ${ }^{10}$ to remove metal and organic contamination. Subsequently a high-lifetime $\mathrm{BBr}_{3}$ diffusion and oxide passivation was performed. This consisted of the deposition of a boron silicate glass at $850{ }^{\circ} \mathrm{C}$ for $20 \mathrm{~min}$, a short $\mathrm{N}_{2}$ drive-in at $850{ }^{\circ} \mathrm{C}$ for $20 \mathrm{~min}$, a dry oxidation at $900{ }^{\circ} \mathrm{C}$ for $30 \mathrm{~min}$, a removal of the oxide in $\mathrm{HF}$, a dry oxidation at $T_{\mathrm{ox}}$ for $t_{\mathrm{ox}}$, and an $\mathrm{N}_{2}$ anneal performed at $T_{\mathrm{ox}}$ for $30 \mathrm{~min}$, where $T_{\mathrm{ox}}$ and $t_{\mathrm{ox}}$ are supplied in Table I. All but two of the samples also received a forming-gas anneal (FGA) at $400{ }^{\circ} \mathrm{C}$ for $30 \mathrm{~min}$ in $95 \% \mathrm{Ar}$ and $5 \% \mathrm{H}_{2}$. This procedure led to samples with a sheet resistance between 200 and $335 \Omega / \mathrm{sq}$, an oxide thickness of $35 \pm 5 \mathrm{~nm}$, and an initial effective lifetime greater than $1 \mathrm{~ms}$. The resulting diffusions and the quality of the passivation are similar to that used in high-efficiency silicon solar cells. ${ }^{7}$

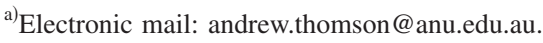

To characterize the increasing recombination and the temperature dependence of the degradation, the samples were stored in air at $25,50,75$, and $100{ }^{\circ} \mathrm{C}$. The recombination was monitored over 160 days, where prior to each measurement the samples were cooled to room temperature. This procedure was effective in characterizing degradation of samples stored above room temperature because the time taken to cool and measure the samples was much shorter than their degradation time constants.

The WCT-100 photoconductance instrument ${ }^{11}$ was employed to measure the effective lifetime $\tau_{\mathrm{eff}}$ as a function of excess minority carrier concentration $\Delta n$. Extraction of the initial $J_{0 e}$ and $\tau_{\text {bulk }}$ was performed by the method devised by Kane and Swanson ${ }^{2}$ but with modern values for the intrinsiccarrier concentration $n_{i}$ (Ref. 12) and combined carrier mobility $\mu_{n}+\mu_{p} .{ }^{13}$ This method could not be used after the samples degraded because the increase in emitter recombination caused $\Delta n$ to vary significantly across the wafer thickness. ${ }^{14}$ Instead, $\tau_{\text {bulk }}$ was assumed constant throughout the experiment, a reasonable assumption for $n$-type silicon, ${ }^{15}$ and changes in $\tau_{\text {eff }}$ were attributed to changes in $J_{0 e}$. This method to determine $J_{0 e}$ avoided distortions in the measurement process owing to the nonuniform $\Delta n$ profile caused by large recombination at the diffused surfaces.

Figure 1 plots the $J_{0 e}$ of boron diffusions stored at room temperature as a function of time. These samples were prepared with oxidation recipe 1 (Table I). The $J_{0 e}$ of each sample increased from $30-80$ to $1000-1400 \mathrm{fA} / \mathrm{cm}^{2}$, saturating after $\sim 1.0 \times 10^{7} \mathrm{~s}(\sim 120$ days $)$. The degradation was similar, irrespective of whether the samples received an FGA or whether the wafer resistivity was 5 or $1000 \Omega \mathrm{cm}$.

TABLE I. Oxidation temperature $T_{\mathrm{ox}}$ and time $t_{\mathrm{ox}}$ and the subsequent sheet resistance $R_{s}$.

\begin{tabular}{cccc}
\hline \hline Recipe & $\begin{array}{c}T_{\text {ox }} \\
\left({ }^{\circ} \mathrm{C}\right)\end{array}$ & $\begin{array}{c}t_{\text {ox }} \\
(\mathrm{min})\end{array}$ & $\begin{array}{c}R_{s} \\
(\Omega / \mathrm{sq})\end{array}$ \\
\hline 1 & 1100 & 6 & 200 \\
2 & 1000 & 40 & 265 \\
3 & 900 & 90 & 335 \\
\hline \hline
\end{tabular}




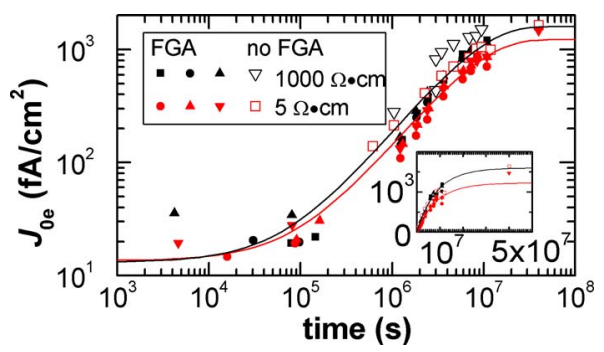

FIG. 1. (Color online) Emitter saturation current $J_{0 e}$ as a function of time for eight samples stored in air at room temperature. As denoted in the legend, the data represents samples fabricated on 5 and $1000 \Omega \mathrm{cm} n$-type silicon, and samples that received and did not receive an FGA. The lines are leastsquares fits of Eq. (2) to the data of FGAed samples for each wafer resistivity. The inset plots the data on linear scales.

The degradation was also similar when the samples were illuminated by a halogen lamp at an intensity of $1 \mathrm{~mW} / \mathrm{cm}^{2}$.

The degradation of the samples stored at $25{ }^{\circ} \mathrm{C}$ followed a first-order exponential,

$$
J_{0 e}=J_{0 e, \text { initial }}+J_{0 e, \text { deg }}\left[1-\exp \left(-t / \tau_{1}\right)\right],
$$

where $J_{0 e \text {,initial }}$ and $J_{0 e, \text { deg }}$ are the initial and increase in $J_{0 e}$, and $\tau_{1}$ is the time constant of the reaction. The lines in Fig. 1 are a least-squares fit to the data of the FGAed samples for each resistivity. Table II lists the best-fit parameters.

Figure 2 plots the results of boron diffusions stored at $100{ }^{\circ} \mathrm{C}$ as a function of time. These samples were prepared with oxidation recipes 1,2 , and 3 on $1000 \Omega \mathrm{cm}$ silicon. The $J_{0 e}$ of all was found to increase from 15-80 to $500-800 \mathrm{fA} / \mathrm{cm}^{2}$. This ten to 20 fold increase in $J_{0 e}$ occurred irrespective of the oxidation recipe but was less than the 30-45 fold increase observed at room temperature. Unlike the samples stored at $25{ }^{\circ} \mathrm{C}$, the degradation does not follow a first-order exponential. Instead, it more closely follows a second-order exponential,

$$
\begin{aligned}
J_{0 e}= & J_{0 e, t 0}+J_{0 e, \operatorname{deg} 1}\left[1-\exp \left(-t / \tau_{1}\right)\right] \\
& +J_{0 e, \operatorname{deg} 2}\left[1-\exp \left(-t / \tau_{2}\right)\right],
\end{aligned}
$$

where $J_{0 e, t 0}, J_{0 e, \operatorname{deg} 1}$, and $J_{0 e, \operatorname{deg} 2}$ are the initial and increase in $J_{0 e}$, and $\tau_{1}$ and $\tau_{2}$ are the time constants of the degradation reactions. Figure 2 includes the lines of best fit for samples prepared with each oxidation recipe. Thus, storing at $100{ }^{\circ} \mathrm{C}$ allowed the observation of a fast degradation reaction, observed at room temperature, and a second slower degradation

TABLE II. Parameters from fitting of Eq. 3 to $J_{0 e}(t)$ for samples fabricated on $1000 \Omega \mathrm{cm} n$-type silicon. The increase in recombination $\left(J_{0 e, \operatorname{deg} 1}\right.$, $\left.J_{0 e, \operatorname{deg} 2}\right)$ and the time constants $\left(\tau_{1}, \tau_{2}\right)$ are presented with errors representing the $95 \%$ confidence interval.

\begin{tabular}{cccccccc}
\hline \hline \multicolumn{2}{c}{ Sample } & & \multicolumn{2}{c}{ Fast degradation } & & \multicolumn{2}{c}{ Slow degradation } \\
\cline { 1 - 1 } \cline { 7 - 8 } \begin{tabular}{c} 
Temp \\
\cline { 7 - 8 }$\left({ }^{\circ} \mathrm{C}\right)$
\end{tabular} & Recipe & & $\begin{array}{c}J_{0 e}, \operatorname{deg} 1 \\
\left(\mathrm{fA} / \mathrm{cm}^{2}\right)\end{array}$ & $\begin{array}{c}\tau_{1} \times 10^{5} \\
(\mathrm{~s})\end{array}$ & & $\begin{array}{c}J_{0 e}, \operatorname{deg} 2 \\
\left(\mathrm{fA} / \mathrm{cm}^{2}\right)\end{array}$ & $\begin{array}{c}\tau_{2} \times 10^{5} \\
(\mathrm{~s})\end{array}$ \\
\hline 25 & 1 & & $952 \pm 40$ & $8.9 \pm 0.4$ & $\ldots$ & $\ldots$ \\
50 & 1 & & $240 \pm 50$ & $3.2 \pm 1$ & & $1100 \pm 600$ & $25 \pm 29$ \\
75 & 1 & & $210 \pm 30$ & $2.0 \pm 0.5$ & & $800 \pm 300$ & $46 \pm 60$ \\
100 & 1 & & $190 \pm 20$ & $1.9 \pm 0.5$ & & $500 \pm 100$ & $35 \pm 42$ \\
100 & 1 & & $150 \pm 20$ & $2.1 \pm 0.8$ & & $390 \pm 40$ & $91 \pm 30$ \\
100 & 2 & & $120 \pm 10$ & $2.5 \pm 0.8$ & & $310 \pm 20$ & $85 \pm 20$ \\
100 & 3 & & $180 \pm 20$ & $1.0 \pm 0.3$ & & $590 \pm 30$ & $76 \pm 10$ \\
\hline \hline
\end{tabular}

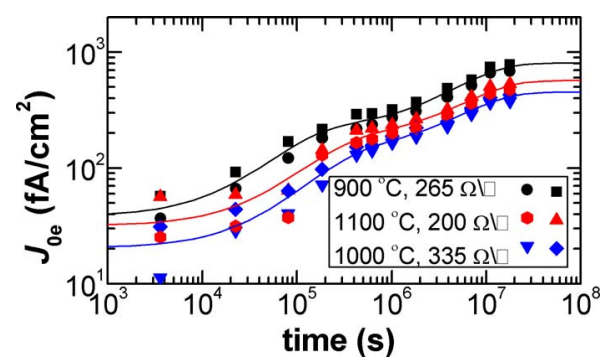

FIG. 2. (Color online) Emitter saturation current $J_{0 E}$ as a function of time for three samples stored in air at $100{ }^{\circ} \mathrm{C}$. The samples were fabricated from $1000 \Omega \mathrm{cm} n$-type silicon and received oxidation recipes 1,2 , and 3 . The lines are least-squares fits of Eq. 3 to the data.

that could not be observed at room temperature.

Table II lists the fast and slow degradation time constants and $J_{0 e}$ increase from the lease-squares fit of Eq. (2) to $J_{0 e}(t)$ for samples stored above $25^{\circ} \mathrm{C}$, and Eq. (1) for samples stored at $25^{\circ} \mathrm{C}$, as the slow degradation process was not observable at room temperature. The error ranges represent the $95 \%$ confidence intervals and these indicate there is a low uncertainty of the fast time constant $\tau_{1}$ and a larger uncertainty for the slow time constant $\tau_{2}$, where it becomes reasonable for samples stored at $100{ }^{\circ} \mathrm{C}$. The table shows that $\tau_{1}$ is ten to 40 times shorter than $\tau_{2}$ highlighting the different time constants of the reactions. We also find the degradation magnitude reduces with increasing storage temperature, in agreement with following annealing results.

The activation energy $E_{a}$ of the fast reaction is $0.19 \pm 0.5 \mathrm{eV}$ as determined by performing an Arrhenius plot of the reaction rates for samples stored at 25, 50, 75, and $100{ }^{\circ} \mathrm{C}$. The reaction rates for $E_{a}$ calculation were taken to be the inverse of $\tau_{1}$ the time constant of the fast reaction.

Two other reports have observed the magnitude of this degradation reaction. First, Zhao et al. ${ }^{9}$ measured a decrease in $V_{\text {oc }}$ of $n$-type PERT solar cells after two to three years storage in the dark at room temperature. The maximum and average decrease in $V_{\text {oc }}$ corresponds to an increase in $J_{0 e}$ of 3300 and $270 \mathrm{fA} / \mathrm{cm}^{2}$, respectively, in agreement with the results presented in Fig. 1. Here, the equivalent $J_{0 e}$ was determined using the single diode model of a solar cell, as in Ref. 16. Second, Altermatt et al. ${ }^{4}$ found the $J_{0 e}$ of oxidepassivated boron diffusions of resistivity $31-213 \Omega /$ sq to increase significantly when left in the dark for two years. When grown with in situ trichloroethane (TCA) the samples degraded to $400-500 \mathrm{fA} / \mathrm{cm}^{2}$, whereas without TCA, the $J_{0 e}$ of the samples of this study degraded to $\sim 2000 \mathrm{fA} / \mathrm{cm}^{2}$, in agreement with the data presented in Fig. 1. These studies indicate boron diffusions degrade irrespective of resistivity and is not limited to the procedure used in this report.

The mechanism that underlies the degradation was examined further by annealing the sample at increasing temperature. One of the samples that degraded at room was first annealed in air at temperatures ranging from 25 to $275^{\circ} \mathrm{C}$ using the temperature and injection-dependent lifetime spectroscopy system described by Paudyal et al. ${ }^{17}$ This system permitted a monitoring of $\tau_{\text {eff }}$ during the annealing so that it could be stopped once it saturated. The system was then cooled to $25{ }^{\circ} \mathrm{C}$ to measure $J_{0 e}$ to avoid any temperature dependence in $J_{0 e}$. To complete the experiment, the samples were annealed in $\mathrm{N}_{2}$ at $400{ }^{\circ} \mathrm{C}$ in a quartz furnace for $30 \mathrm{~min}$ and the $J_{0 e}$ was remeasured. 


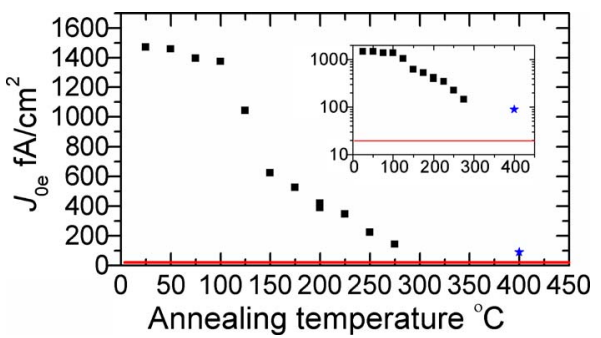

FIG. 3. (Color online) Emitter saturation current $J_{0 e}$ of a degraded sample that had been stored for over one year at room temperature. The red line shows the predegradation $J_{0 e}$. The symbols plot $J_{0 e}$ after an anneal in air at increasing temperature. (The final anneal at $400{ }^{\circ} \mathrm{C}$ was performed in $\mathrm{N}_{2}$ ). The inset plots $J_{0 e}$ on log scale.

The above procedure resulted in the $J_{0 e}$ versus annealing temperature plotted in Fig. 3. The red line indicates the asfabricated $J_{0 e}$. From this plot we see that there is a large reduction in $J_{0 e}$ between 100 and $175^{\circ} \mathrm{C}$, possibly indicating that one of the two mechanisms that caused the increase in recombination is strongly annealed. There is a continual smaller reduction in recombination annealing above $175{ }^{\circ} \mathrm{C}$. Thus, the annealing significantly improved $J_{0 e}$ but even after a $400{ }^{\circ} \mathrm{C}$, it remains four times its as-fabricated level.

We propose the degradation is caused by a reaction between the $\mathrm{Si}-\mathrm{SiO}_{2}$ interface and atomic hydrogen, ${ }^{18}$ where $P_{b}$ defects ${ }^{19}$ are formed with an $E_{a}$ of $0.2 \mathrm{eV}^{20}$ A possible source of $\mathrm{H}^{+}$specific to these structures is boron-hydrogen (BH) complexes created in the emitter during hightemperature processing, where the dissociation of $\mathrm{BH}$ pairs has an $E_{a}$ of $0.6 \mathrm{~V}^{21}$ Thus, for this mechanism to be consistent with the observed $E_{a}$ of the fast reaction $(0.23 \pm 0.05 \mathrm{eV})$, the initial degradation cannot be limited by $\mathrm{BH}$ dissociation, either because (i) there is an initial excess of $\mathrm{H}^{+}$or (ii) the pre-exponential reaction constant of the $\mathrm{BH}$ dissociation is much higher than that of the $P_{b}$ generation. There may be alternative sources of $\mathrm{H}^{+}$causing this degradation such as from the passivating oxide or the atmosphere, but these are not limited to boron-diffused structures.

${ }^{1}$ A. G. Aberle, P. P. Altermatt, G. Heiser, S. J. Robinson, A. Wang, J. Zhao, U. Krumbein, and M. A. Green, J. Appl. Phys. 77, 3491 (1995).

${ }^{2}$ D. E. Kane and R. M. Swanson, Proceedings of the 18th IEEE Photovoltaic Specialists Conference, Las Vegas, NV, 1985 (unpublished).

${ }^{3}$ R. R. King, R. A. Sinton, and R. M. Swanson, IEEE Trans. Electron Devices 37, 365 (1990).

${ }^{4}$ P. P. Altermatt, H. Plagwitz, R. Bock, J. Schmidt, R. Brendel, M. J. Kerr, and A. Cuevas, Proceedings of the 21st European Photovoltaic Solar Energy Conference, Dresden, Germany, 4-8 September 2006 (unpublished).

${ }^{5}$ R. R. King and R. M. Swanson, IEEE Trans. Electron Devices 38, 1399 (1991).

${ }^{6}$ J. Zhao, A. Wang, P. Altermatt, and M. A. Green, Appl. Phys. Lett. 66, 3636 (1995)

${ }^{7}$ J. Zhao, A. Wang, P. P. Altermatt, M. A. Green, J. P. Rakotoniaina, and O. Breitenstein, Proceedings of the IEEE, Photovoltaic Specialists Conference, Piscataway, NJ, 2002 (unpublished), pp. 218-221.

${ }^{8}$ J. Schmidt, M. Kerr, and A. Cuevas, Semicond. Sci. Technol. 16, 164 (2001)

${ }^{9}$ J. Zhao, J. Schmidt, A. Wang, G. Zhang, B. Richards, and M. Green, Proceedings of the Third World Conference on Photovoltaic Energy Conversion, Osaka, Japan, 2003 (unpublished).

${ }^{10}$ W. Kern and D. A. Puotinen, RCA Rev. 31, 187 (1970).

${ }^{11}$ R. A. Sinton and R. M. Swanson, IEEE Trans. Electron Devices 34, 1380 (1987).

${ }^{12}$ A. B. Sproul and M. A. Green, J. Appl. Phys. 70, 846 (1991).

${ }^{13}$ P. P. Altermatt, J. Schmidt, M. Kerr, G. Heiser, and A. G. Aberle, Proceedings of the 16th European Photovoltaic Solar Energy Conference, Glasgow, Scotland, 2000 (unpublished).

${ }^{14}$ H. Nagel, C. Berge, and A. G. Aberle, J. Appl. Phys. 86, 6218 (1999).

${ }^{15}$ L. J. Geerligs and D. H. Macdonald, Prog. Photovoltaics 12, 309 (2004).

${ }^{16}$ J. G. Fossum, IEEE Trans. Electron Devices 24, 322 (1977).

${ }^{17}$ B. B. Paudyal, K. R. McIntosh, D. H. Macdonald, B. S. Richards, and R. A. Sinton, Prog. Photovoltaics 16, 609 (2008).

${ }^{18}$ E. Cartier and J. H. Stathis, Microelectron. Eng. 28, 3 (1995).

${ }^{19}$ A. Stesmans, Phys. Rev. Lett. 70, 1723 (1993).

${ }^{20}$ S. N. Rashkeev, D. M. Fleetwood, R. D. Schrimpf, and S. T. Pantelides, Phys. Rev. Lett. 87, 165506 (2001).

${ }^{21}$ C. P. Herrero, M. Stutzmann, A. Breitschwerdt, and P. V. Santos, Phys Rev. B 41, 1054 (1990). 